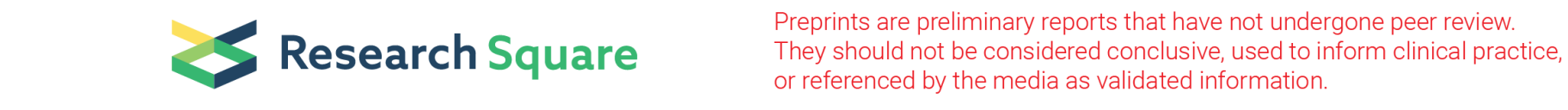

\title{
Development of sorghum mutant genotypes and analysis of their agro- morphological diversity
}

\author{
Abera Takele ( $\square$ aberatakele91@gmail.com ) \\ Addis Ababa University \\ Tileye Feyisa \\ Addis Ababa University \\ Tesfaye Disasa \\ National Agricultural Biotechnology Research Center
}

\section{Research Article}

Keywords: EMS, LD50, morphological variability, mutagenesis, Sorghum

Posted Date: May 18th, 2021

DOI: https://doi.org/10.21203/rs.3.rs-457881/v1

License: (c) (1) This work is licensed under a Creative Commons Attribution 4.0 International License. Read Full License 


\section{Abstract}

Sorghum is one of the most important cereal grains in Africa's Sub-Saharan region, used for human consumption and animal feed, but its production is hampered by biotic and abiotic constraints, necessitating genetic improvement of sorghum. The goal of this experiment was to use the ethyl methane sulfonate induced mutation technique to develop superior genotypes for sorghum production and quality for food and industry in order to achieve food security. The concentration of EMS was initially optimized by calculating LD 50 . Both Argity and Dekeba genotypes were treated with six different concentrations of EMS $(0.10,0.25,0.30,0.50,0.75$ and $1.00 \%)$ and three different soaking periods ( 7,8 and 9 hrs). The $0.25 \%$ EMS concentration at 8 hrs was chosen because it had a $50 \%$ seed survival rate and the highest frequency of mutations to generate $M_{1}$ seeds. From M2 and M3, about 4000 and 2000 mutant populations were screened, respectively. For trait characterization, 190 mutated lines were selected from a mutant population of $2000 \mathrm{M}_{2}$. The 190 mutant populations and two parents were evaluated for genetic diversity, character association, and genetic divergence. For the observed quantitative phenotypic traits, analyses of variance showed substantial inter-population difference. When compared to their parent cultivars, the study mean of six treatment populations in each cultivar showed significantly superior quantitative phenotypic traits. Plant height, flowering date, maturity date, stem diameter, grain weight, and thousand seed weight varied with $81.48,77,42.03,56.11,11.44$, and $96.68 \%$ heritability in the mutant lines, according to agro-morphological characterization. The elite mutants were identified using principal component analysis based on their agro-morphological traits, while Pearson's correlation findings showed a positive correlation between yield component traits. Finally, our research allowed the identification of new promising mutant genotypes that could be tested in multi-local trials to assess their agronomic efficiency.

\section{Introduction}

Sorghum (Sorghum bicolor (L.) Moench) is a high-yielding grain that thrives in arid and semi-arid climates (Mwadalu and Mwangi, 2013; Eldeen et al., 2020). Sorghum is a C4 crop with chromosome $2 \mathrm{n}=20$ and $7.35 \times 108$ bp of DNA per $1 \mathrm{C}$ nucleus (Biswas et al., 2020). It is the fifth most important cereal crop in the world, after maize (Zea mays L.), wheat (Triticum aestivum L.), rice (Oryza sativa L.), and barley (Hordeum vulgare L.), based on total grain production and subsistence crops, for more than 500 million people in over 90 countries, especially in Africa, Asia, and Latin America, where drought and pests are the main constraints (Deng, 2020; Hiloidhari et al., 2020). Sorghum is one of the most important stable cereal crops in Ethiopia, after Tef (Eragrostis tef (Zucc.) Trotter.) and maize (Zea mays L.) (Barretto et al., 2020; Belete, 2020; Mahilet, 2020). After Sudan, it is Africa's second-largest sorghum producer ( Tonapi et al., 2020; Iseki et al., 2021). Sorghum is a multipurpose crop because the grain is used to make food, beverages, and animal feed as well as industrial raw materials ( Parmar et al., 2018; Aleme Asrate, 2020; Velmurugan et al., 2020).

Despite its enormous economic value, sorghum productivity in Ethiopia and thrsoughout Africa remains poor (Taylor, 2019). The national average sorghum productivity in Ethiopia is estimated to be 2.74 tons per hectare, compared to global 3.5 tons per hectare. The poor productivity is due to a variety of biotic and abiotic constraints (Daigaku et al., 2004). Drought and soil acidity are the most common abiotic factors that cause yield loss in sorghum production around the world (Horn and Shimelis, 2020). Diseases, insects, and weeds are the most common abiotic stresses that cause of yield loss in sorghum. Pest resistance/tolerance, especially to stalk borer, weevils, and striga weed, is thus desirable in sorghum to ensure the survival of the millions of people who rely on it ( Mahuku et al., 2017; Abeje et al., 2020). Traditional breeding has its own drawbacks due to the small number of markers that are affected by the climate. As a result of the faster breeding process, sorghum varieties with multiple resistance and desirable traits such as biotic and abiotic resistance can be produced (Gienapp et al., 2019; Oladosu et al., 2019). The recent advances in molecular biology, mutation breeding, genomics, gene mapping, and bioinformatics offer an excellent opportunity to support the sorghum development program in this regard (Sahu et al., 2020; Sedlazeck et al., 2018).

Ethyl Methane Sulphonate (EMS) is a potent chemical mutagen capable of inducing high-density mutations in the genomes of a wide range of species (Kumar et al., 2021; Taheri et al., 2017). EMS mutagenesis is a workhorse technique for the study of recalcitrant metabolic and signal in disorders. TILLING has found a few mutated genes in sorghum based on individual amplicons. EMS-induced mutations can now be cataloged on a wide scale as a result of recent developments in high-thrsoughput next-generation sequencing (Irshad et al., 2020; Martinez et al., 2020).

Ethiopian sorghum has been used in a variety of traditional and molecular studies for various purposes (Belay and Wale, 2021; Tirfessa et al., 2020). The majority of this research, however, concentrated on grain sorghums or their wild relatives, and there is an extensive study of sweet sorghum germplasm selection and genotypes from Ethiopia. Furthermore, no effort has been made to develop novel sorghum genotypes based on mutation breeding with some biotic and abiotic resistance/tolerance and QTL from currently screened resistant materials of lines that are initially screened and resulted from mutation breeding. Therefore, using a mutation breeding strategy, it is critical to conduct sorghum breeding to recognize novel genes that could encode traits of interest. Such work will contribute to and solve the problem of food security and nutrition through the use of innovative solution tools, technology, policies, and methods to improve and maintain food security and nutrition. Therefore, the objective of the present study is to develop superior genotypes for sorghum production and quality for food and industry in order to achieve food security.

\section{Materials And Methods Experimental materials and EMS treatment optimization}

$M_{0}$ seeds of two sorghum varieties, Argity and Dekeba, were obtained from Melkasa Agricultural Research Center, Ethiopia which are improved varieties, for this analysis. The chemical mutagen ethyl methane sulfonate (EMS) was obtained from the National Agricultural Biotechnology Research Center, Ethiopia. The concentration of EMS was initially optimized by calculating LD $_{50}$ values depending on germination rate and survival percentage (Ndung'u, 2009). The research was carried out in a lab setting under controlled conditions with three replications. For each replication, one hundred seeds of each genotype were presoaked in double distilled water overnight. Then both genotypes were treated with six different concentrations of EMS $(0.10,0.25,0.30,0.50,0.75$ and 1.00 $\%)$ and three different soaking periods $(7,8$ and $9 \mathrm{hrs})$ at $25^{\circ} \mathrm{C}$ with continuous shaking at $100 \mathrm{rpm}$. To remove residual EMS from the treated seeds, they were 
thoroughly washed 3-4 times under running tap water. The seeds were kept in Petri plates on Whatmann paper disks that had been soaked in distilled water. Only distilled water was used to treat the control seeds. To keep the paper moist, distilled water was added three times a day with an 8-hour gap between applications. All sprouted seeds were considered germinated, regardless of whether the seedlings that resulted were normal or abnormal. On the 9th day after treatment (DAT), the germinated seeds from each Petri plate were counted. The average of the three replications was used to measure the percent seed germination, and the data was analyzed to determine the $\mathrm{LD}_{50}$.

\section{Generating mutant lines}

A total of about $20,000 \mathrm{M}_{0}$ seeds (10,000 Argity and 10,000 Dekeba seeds) were presoaked in double distilled water for 12 hrs. The seeds were then treated with $0.25 \%(\mathrm{v} / \mathrm{v})$ EMS solution for $8 \mathrm{hrs}$ at $25^{\circ} \mathrm{C}$. The concentration was chosen because it had a $50 \%$ seed survival rate and the highest frequency of mutations to generate $M_{1}$ seeds. Before sowing in the field, all treated seeds was thoroughly washed three times under tap water to remove any excess mutagen adhered to the seed surface. Seeds that had been mutagenized were air-dried and prepared for planting.

\section{Experimental design and development of mutagenized populations}

The air-dried sorghum seeds were planted at a density of 120,000 seeds per hectare at the Ambo University, Guder campus, which is located at an altitude of 1900 meters above sea level with $37^{\circ} 46^{\prime} \mathrm{E}$ and $8^{\circ} 58^{\prime} \mathrm{N}$. The net field size was $22 \times 40$ meters, with 13 blocks (each $3 \times 1.8$ meters), 0.6 meters (row to row) and 0.3 meters (seed to seed) width. During 2018 and 2019, mutagenized $M_{1}$ seeds were sown in an alpha lattice design and self-fertilized to produce $M_{1}$ plants, along with respective controls. After seed sowing, the field was irrigated at regular intervals, and weeding was done at the seedling and flowering stages. To avoid cross pollination, each panicle was covered with a 400-weight rain-proof pollination bag (Lawson Bags) before anthesis. Each bag was injected with $5 \mathrm{ml}$ Chlorpyrifos (Dow Agro Sciences) to control earworms. At maturity stage, all $\mathrm{M}_{1}$ plants were manually harvested and thrseshed individually to collect $\mathrm{M}_{2}$ seeds. Plants with the best appearance and minimal stunting and other mutagenic treatment-related plant deformities were selected. $M_{2}$ seeds were planted in one row per head from 2018 to 2019 . Only panicles that set $10 \%$ or fewer seeds were allowed to proliferate to ensure high mutagenesis. $M_{3}$ progenies were produced from one fertile $M_{2}$ plant from each $M_{2}$ head chain. A total of $2000 M_{3}$ lines were collected from a $4000 M_{2}$ population and stored for further analysis.

\section{Seed germination}

After 21 days of seed sowing, the number of germinated seeds was counted and the percentage of seed germination was determined.

\section{Chlorophyll mutations}

After 24 days of seed sowing in the field, chlorophyll mutants were recorded in the $\mathrm{M}_{2}$ and $\mathrm{M}_{3}$ generation and mutation frequency was calculated.

\section{Agro-morphological characterization of mutants}

In the $\mathrm{M}_{2}$ generation of both varieties, data on twenty three qualitative and quantitative traits were reported (Table 1). For the mutants of the Argity and Dekeba varieties, pedigree methods were used to advance the mutant populations from $M_{1}$ to $M_{3}$, with selection criteria based on plant height, maturity date, stem diameter, plant yield, and related factors. Grain yield and growth parameters were used to select mutants of two varieties in $M_{3}$. Traits that were analyzed and updated using sorghum descriptors from the International Union for the Protection of New Varieties of Plants and the International Board for Plant Genetic Resource (IBPGR, 1993 ). Plant height variations, growth habit, leaf flower, and seed morphological mutant features were registered, and analyzed in the field.

\section{Statistical analysis}

Since different traits were calculated on different scales, the data were standardized to zero mean and unit variance before study. Microsoft Excel 2003 was used to measure descriptive statistics, analysis of variance, and correlation coefficients for all six quantitative traits. The percentage contribution of each trait to total genetic variation was determined using principal component analysis of the traits. Ward's linkage approach was used to conduct agglomerative hierarchical clustering on the Euclidean distance matrix. MINITAB software version 19 was used for this analysis (Minitab, 2013). Phenotypic coefficient of variation (PCV), genotypic coefficient of variation (GCV), genetic advance (GA), and wide sense heritability $\left(\mathrm{h}^{2}\right)$ ( $\mathrm{R}$ Development Core Team, 2011, version 3.6.1) were calculated.

\section{Results}

\subsection{EMS treatment optimization}

The EMS concentrations and soaking time were found to have a significant impact on germination rate. As the soaking time and EMS concentration increased, the germination rate decreased (Fig. 1). ANOVA revealed that soaking time had an impact on germination. The effect of EMS concentrations on germination for three soaking times $(7,8$, and $9 \mathrm{hrs}$ ) revealed that treatment with $0.10 \%$ is not significantly different from the control. Treatment with $0.25 \%$, on the other hand, differed significantly from 0 to $0.10 \%$ and 0.30 to $1.00 \%$, and resulted in a $50 \%$ survival rate. Based on these findings, $0.25 \%$ and exposure for 8 hour was found to be the best condition for the bulk EMS sorghum mutagenesis.

\section{Generating mutant populations}

From 20,000 mutagenized seeds, $4000 \mathrm{M}_{2}$ progenies were produced. Continuously, from $4000 \mathrm{M}_{2}$ mutant populations of Argity $(2,040)$ and Dekeba $(1,960)$ varieties were developed using the optimized treatment protocol. 
Frequency of $M_{2}$ and $M_{3}$ families for specific mutation observed in the field

All of the $4000 \mathrm{M}_{2}$ mutant lines were monitored from seedling to full maturity, with special attention paid to altered seedling phenotypes (Table 1). Plant height variations of up to $19.39 \%$ and $11.76 \%$ of all observable phenotypes were recorded for Dekeba and Argity, respectively, and mostly resulted in dwarfism and semi dwarfism. Albinism was the second most common form of mutation, accounting for $17.34 \%$ for Dekeba and $17.34 \%$ for Argity. Tiny plants, which differ from dwarf plants in that they have smaller organs, made up $8.87 \%$ (Argity) and $4.6 \%$ (Dekeba) of all phenotypic mutants, and these mutants were always related to a later heading date and lower fertility (Table 1).

Table 1. Frequency of $M_{2}$ and $M_{3}$ families segregating for specific mutation observed in the field

\begin{tabular}{|c|c|c|c|c|c|c|c|c|c|c|}
\hline & \multirow{3}{*}{ Phenotype description } & \multirow{3}{*}{ Sym } & \multicolumn{4}{|c|}{$\mathrm{M}_{2}$ generation from 4000 mutant lines } & \multicolumn{4}{|c|}{$M_{3}$ generation from 2000 mutant lines } \\
\hline & & & \multicolumn{2}{|c|}{ Argity variety } & \multicolumn{2}{|c|}{ Dekeba variety } & \multicolumn{2}{|l|}{ Argity variety } & \multicolumn{2}{|c|}{ Dekeba variety } \\
\hline & & & No. Mutant & Freq. (\%) & No. Mutant & Freq. (\%) & No. Mutant & Freq. (\%) & No. Mutant & Freq. (\%) \\
\hline 1 & Dwarf and semi-dwarf & $d w$ & 424 & 11.76 & 380 & 19.39 & 24 & 2.4 & 80 & 8 \\
\hline 2 & Albino & w & 271 & 13.3 & 340 & 17.34 & 27 & 2.7 & 40 & 4 \\
\hline 3 & Narrow leaf & $\mathrm{nrl}$ & 107 & 5.25 & 97 & 4.95 & 7 & 0.7 & 0 & 0 \\
\hline 4 & Multiple tillers & $\mathrm{mtl}$ & 86 & 4.2 & 112 & 5.7 & 19 & 1.9 & 12 & 1.2 \\
\hline 5 & Tiny plants & tny & 181 & 8.87 & 90 & 4.6 & 8 & 0.8 & 9 & 0.9 \\
\hline 6 & Spot leaf lesion & $\mathrm{spl}$ & 121 & 5.9 & 209 & 10.66 & 10 & 1 & 9 & 0.9 \\
\hline 7 & Leaf rolling & Ir & 66 & 3.24 & 72 & 3.67 & 0 & 0 & 0 & 0 \\
\hline 8 & Erect leaf & erl & 44 & 2.16 & 104 & 5.3 & 5 & 0.5 & 5 & 0.5 \\
\hline 9 & Short leaf & shl & 84 & 4.12 & 150 & 7.65 & 0 & 0 & 0 & 0 \\
\hline 10 & Chlorotic leaf & chl & 40 & 1.96 & 54 & 2.76 & 4 & 0.4 & 5 & 0.5 \\
\hline 11 & Adherent leaf & adl & 35 & 1.71 & 19 & 0.97 & 0 & 0 & 0 & 0 \\
\hline 12 & Wide leaf & wdl & 132 & 6.47 & 201 & 10.26 & 12 & 1.2 & 23 & 2.3 \\
\hline 13 & Yellow splotch leaf & ysp & 33 & 1.62 & 25 & 1.28 & 6 & 0.6 & 5 & 0.5 \\
\hline 14 & Undeveloped panicle & udp & 46 & 2.25 & 22 & 1.12 & 0 & 0 & 0 & 0 \\
\hline 15 & Brown mid rib & bmr & 28 & 1.37 & 21 & 1.07 & 30 & 3 & 29 & 2.9 \\
\hline 16 & Hair-ness & hrsn & 18 & 0.92 & 87 & 4.44 & 11 & 1.1 & 31 & 3.1 \\
\hline 17 & Early maturity & ema & 68 & 3.33 & 92 & 4.5 & 80 & 8 & 102 & 10.2 \\
\hline 18 & Late maturity & Ima & 189 & 9.26 & 240 & 12.24 & 29 & 2.9 & 35 & 3.5 \\
\hline 19 & Zebra cross bands & zeb & 51 & 2.5 & 69 & 3.52 & 0 & 0 & 0 & 0 \\
\hline 20 & Early flowering & efl & 72 & 3.53 & 36 & 1.84 & 80 & 8 & 100 & 10 \\
\hline 21 & Late flowering & Ifl & 123 & 6.03 & 168 & 8.57 & 23 & 2.3 & 33 & 3.3 \\
\hline 22 & Variegated leaf & var & 19 & 0.93 & 24 & 1.22 & 0 & 0 & 0 & 0 \\
\hline 23 & Lodging & Idg & 7 & 0.34 & 7 & 0.73 & 0 & 0 & 0 & 0 \\
\hline
\end{tabular}

Phenotypes were named according to Rooney et al. (2009) wherever possible new phenotypes are named using three letter codes according to Brasier et al. (2003). 
Table 2

Analysis of the mean yield and yield components of mutant lines

\begin{tabular}{|c|c|c|c|c|c|c|c|c|c|c|c|c|c|c|c|c|}
\hline \multirow[t]{2}{*}{ Traits } & \multicolumn{2}{|c|}{ Controls } & \multicolumn{7}{|c|}{ Argity Mutant lines } & \multicolumn{7}{|c|}{ Dekeba Mutant lines } \\
\hline & Argity & Dekeba & Mean & Var. & StDev & MSE & Min & Max & CV & Mean & Var. & StDev & MSE & Min & Max & $\mathrm{C}^{\prime}$ \\
\hline $\mathrm{PH}$ & 210 & 85 & 198.24 & 4177 & 64.63 & 6.60 & 39.00 & 343.00 & 1.88 & 127.20 & 3008 & 54.84 & 5.60 & 40.00 & 290.00 & 7 \\
\hline FD & 95 & 86.66 & 88.15 & 154 & 12.42 & 1.27 & 60.00 & 110.00 & 5.36 & 88.51 & 116 & 10.78 & 1.10 & 70.00 & 113.33 & $1:$ \\
\hline MD & 141.6 & 121.67 & 115.21 & 163 & 12.77 & 1.30 & 91.00 & 141.66 & 3.84 & 117.97 & 223 & 14.93 & 1.52 & 83.33 & 160.00 & 9 \\
\hline SD & 13.15 & 14.49 & 12.945 & 3.05 & 1.745 & 0.178 & 9.133 & 18.847 & 12.10 & 13.351 & 4.28 & 2.070 & 0.211 & 9.227 & 19.32 & $1\}$ \\
\hline GW & 60 & 62 & 62.49 & 173 & 13.15 & 1.34 & 32.33 & 93.00 & 5.26 & 63.07 & 386 & 19.64 & 2.00 & 22.00 & 122.00 & 5. \\
\hline TSW & 35.23 & 34 & 31.962 & 23.1 & 4.808 & 0.491 & 22.727 & 44.743 & 7.08 & 30.497 & 15.8 & 3.975 & 0.406 & 21.620 & 39.843 & 21 \\
\hline
\end{tabular}

PH: Plant height, FD: Flowering date, MD: Maturity date, SD: Stem diameter, GW: Grain weight, TSW: Thousand seed weight, MSE: Mean square error, StDev: Standard deviation, CV: Coefficient of variation

\section{Quantitative traits among $\mathrm{M}_{3}$ mutants}

Across generations, the average plant height of Argity and Dekeba control was $210 \mathrm{~cm}$ and $85 \mathrm{~cm}$, respectively, while the values of the mutants ranged from 39 to $343 \mathrm{~cm}$ for Argity mutants and 40 to $290 \mathrm{~cm}$ for Dekeba mutants (Table 3). The average stem diameter for Argity and Dekeba control was $13.15 \mathrm{~mm}$ and $13.35 \mathrm{~mm}$, respectively. The stem diameter of Argity mutant lines ranged from $9.13 \mathrm{~mm}$ to $18.85 \mathrm{~mm}$, while Dekeba mutant lines ranged from $9.3 \mathrm{~mm}$ to 19.32 $\mathrm{mm}$. The average grain weight per head for Argity mutant lines and Dekeba mutant lines was $62.49 \mathrm{~g}$ and $63.07 \mathrm{~g}$, respectively, and $60 \mathrm{~g}$ and $62 \mathrm{~g}$ for Argity and Dekeba parents. The Argity mutant lines had seed weights ranging from $22.73 \mathrm{~g}$ to $44.7 \mathrm{~g}$, while the Dekeba mutant lines had seed weights ranging from $21.62 \mathrm{~g}$ to $39.84 \mathrm{~g}$. The Argity and Dekeba control lines had seed weights of $35.23 \mathrm{~g}$ and $34 \mathrm{~g}$, respectively. Regardless of generation, twelve Argity mutant lines produced more seeds (92 to $122 \mathrm{~g}$ ) per plant. Similarly, Dekeba mutants (90 to $125 \mathrm{~g}$ ) seeds per head showed similar results.

Table 3

Estimation of mean values of phenotypic and genotypic coefficient of variation in M3 sorghum mutant lines

\begin{tabular}{|lllllllllllll}
\hline Traits & Mean & Ems & Gms & Pms & GV & PV & GCV & PCV & H $^{2}$ & GA & GAM & CV\% \\
\hline PH & 162.41 & 9.3 & 91.15 & 81.85 & 40.925 & 50.22 & 3.94 & 4.36 & 81.48 & 11.91 & 7.34 & 1.88 \\
FD & 88.33 & 22.4 & 172.41 & 150.01 & 75.005 & 97.40 & 9.80 & 11.17 & 77.00 & 15.68 & 17.75 & 5.36 \\
\hline MD & 116.41 & 20 & 49 & 29 & 14.5 & 34.5 & 3.27 & 5.05 & 42.03 & 5.09 & 4.37 & 3.84 \\
SD & 13.15 & 2.53 & 9 & 6.47 & 3.235 & 5.76 & 13.67 & 18.26 & 56.11 & 2.78 & 21.14 & 12.10 \\
GW & 61.79 & 10.57 & 13.3 & 2.73 & 12.365 & 11.93 & 1.89 & 5.59 & 11.44 & 0.82 & 1.32 & 5.26 \\
\hline TSW & 31.23 & 4.89 & 289.29 & 284.4 & 89.2 & 98.09 & 38.18 & 38.83 & 96.68 & 24.19 & 77.45 & 7.08
\end{tabular}

Ems: Error mean square, Gms: Genotype mean square, Pms: Phenotype mean square, GV: Genotype variation, PV; Phenotype variation, GCV: Genotypic coefficient of variation, PCV: Phenotypic coefficient of variation, $\mathrm{h}^{2}$ bs: broad sense heritability, GA: genetic advance as \% of the mean, GAM: genetic advance as \% of mean.

\section{Heritability of agro morphological traits in the mutants}

The PV ranged from $98.09 \%$ for thousand seed weight to 5.76\% for stem diameter. Flowering date had the highest PV values (97.40\%), while plant height, maturity date, and grain weight per head had $50.22,34.5$, and $11.93 \%$, respectively. The recorded GV values for thousand seed weight and stem diameter ranged from $89.2-3.25 \%$, respectively. A PCV and a GCV were found in all of the traits tested. In the mutants, the GA as a percentage of the mean ranged from $0.82 \%$ (GW) to $24.19 \%$ for TSW. The heritability of TSW (96.48\%), PH (81.48\%), FD (77\%) and SD (56\%) were scored. All had high heritability values, while the remaining traits had values below $50 \%$ (Table 3 ).

\section{Genotype clustering based on principal components analysis}

Table 4 shows the agronomic character correlation coefficients with yield and yield component traits in $\mathrm{M}_{3}$ mutants. PH was highly significant and positively associated to FD, MD, and SD with $r=0.970, r=0.551$, and $r=0.795$, respectively, according to the Pearson's coefficient between agro-morphological characters across the generations (from $\mathrm{M}_{1}$ to $\mathrm{M}_{3}$ ). The TSW and FD were also positively correlated with grain weight per plant $(r=0.39$ and $r=0.573$, respectively). PH and MD were both significantly and negatively correlated ( $r=0.507$ and 0.879 , respectively) (Table 4$)$. 
Table 4

Estimation of Pearson's correlation between the agro morphological traits in the $M_{3}$ of the mutant lines screened at Gudar, 2018-2020.

\begin{tabular}{|c|c|c|c|c|c|c|}
\hline Correlation & $\mathrm{PH}$ & FD & MD & SD & GW & TSW \\
\hline $\mathrm{PH}$ & 1 & & & & & \\
\hline FD & 0.970 & 1 & & & & \\
\hline MD & 0.551 & 0.001 & 1 & & & \\
\hline SD & 0.795 & 0.783 & 0.078 & 1 & & \\
\hline GW & 0.008 & 0.573 & 0.424 & 0.103 & 1 & \\
\hline TSW & -0.507 & 0.279 & -0.879 & 0.807 & 0.390 & 1 \\
\hline
\end{tabular}

\section{Cluster analysis}

Based on the six quantitative phenotypic traits recorded, the 190 mutated lines and two control populations from Argity and Dekeba were clustered. Four clusters in all mutant lines and two controls were observed (Fig. 2). For all mutant lines, the phylogenetic relationships were represented in a Dendrogram (complete linkage, Euclidian distance) (Fig. 3). In the dendrogram, the clustering pattern of different mutant lines revealed differences in cluster number and similarity within clusters, as well as hierarchical categorization within and among clusters. The two sorghum varieties' mutant lines formed four clusters, with cluster numbers $84,65,29$, and 14 for C1, C2, C3, and C4 respectively (Fig. 2). It was noteworthy that the control population formed an independent cluster in all mutant lines, indicating that mutagenic treatments caused significant genetic variations in the quantitative phenotypic traits of the mutants. The interpopulation dissimilarity matrix showed that the C2 and C4 in all mutant lines have the highest squared Euclidean distance (219.9), while the C2 and C3 in all mutant lines have the lowest (36.9) (Table 5).

Table 5

Distances between Cluster Centroids

\begin{tabular}{|c|c|c|c|c|}
\hline & Cluster 1 & Cluster2 & Cluster3 & Cluster4 \\
\hline Cluster 1 & 0.000 & & & \\
\hline Cluster 2 & 118.822 & 0.000 & & \\
\hline Cluster 3 & 82.975 & 36.933 & 0.000 & \\
\hline Cluster 4 & 101.360 & 219.912 & 183.650 & 0.000 \\
\hline
\end{tabular}

In both mutant lines, the highest inter-cluster gap (219.9) was found between Cluster two and Cluster four, while the lowest was found between Cluster two and Cluster three (36.9). Table 5 shows the cluster mean of the three distant clusters for the six quantitative phenotypic traits. Cluster four had the highest mean plant height $(308.85 \mathrm{~cm})$, and Cluster three had the highest mean stem diameter, grain weight per head, and thousand seed weight (13.6 $\mathrm{cm}, 61.3 \mathrm{~g}$, and $31.25 \mathrm{~g}$, respectively). As a result, the mutant line that belongs to this cluster could be screened for the selection of high yielding sorghum plants (Table 6 ).

Table 6

Cluster Centroids

\begin{tabular}{|llllll|}
\hline Traits & Cluster $\mathbf{1}$ & Cluster $\mathbf{2}$ & Cluster 3 & Cluster $\mathbf{4}$ & Grand centroid \\
\hline PH & 207.952 & 89.435 & 125.400 & 308.857 & 162.718 \\
\hline FD & 88.563 & 87.487 & 90.057 & 87.262 & 88.330 \\
\hline MD & 113.983 & 116.515 & 121.897 & 121.548 & 116.587 \\
\hline SD & 13.114 & 12.982 & 13.606 & 13.173 & 13.148 \\
\hline GW & 59.155 & 67.185 & 61.299 & 53.452 & 61.781 \\
\hline TSW & 31.254 & 31.363 & 31.252 & 30.416 & 31.230 \\
\hline PH: Plant height, FD: Flowering date, MD: Maturity date, SD: Stem diameter, GW: Grain weight, TSW: Thousand seed weight \\
\hline
\end{tabular}

\section{Principle component analysis (PCS)}

Table 7 shows the traits that helped to distinguish the different treated mutant populations. Plant height is the largest group with negative loading on PC1, while grain weight per head (0.665) is the largest group with positive loading on PC1 (-0.397). In mutant lines, the maturity date (0.709) showed positive loading. For plant height PC3 and PC4 are the main groups with positive loading 0.52 and $0.668 \%$, respectively. The latent roots (Eigen value) of the six derived principal components PC1, PC2, PC3, PC4, PC5 and PC6 from the original data were more than one, accounting for 21.1, 65.3, 17.1, 52.8, 11.8, 10.8 \% of the total variation in the mutant population, respectively. As a result, the original data set's overall variance is broken down into independent components, with their combined variation of $53.1,54.4,61.5,77.4,89.2$, and $98 \%$, respectively. The loading plots of the biometrical traits in PC2 and PC4 clearly 
demonstrated that yield-related traits had made a significant contribution to the overall genetic variance. For the observed quantitative traits, the distribution pattern also showed that there was a large amount of heterogeneity among the mutant populations.

Table 7

Principal components analysis showing the contribution of six quantitative traits among the sorghum mutant lines

\begin{tabular}{|lllllll|}
\hline Traits & \multicolumn{7}{l|}{ Principal components (PCS) } \\
\cline { 2 - 7 } & PC1 & PC2 & PC3 & PC4 & PC5 & PC6 \\
\hline Plant height (cm) & -0.397 & -0.013 & $\mathbf{0 . 5 1 2}$ & $\mathbf{0 . 6 6 8}$ & -0.132 & -0.343 \\
\hline Flowering date & 0.227 & 0.569 & 0.472 & -0.087 & $\mathbf{0 . 6 2 8}$ & 0.010 \\
\hline Maturity date & 0.052 & $\mathbf{0 . 7 0 9}$ & 0.005 & -0.141 & -0.683 & -0.093 \\
\hline Stem diameter (mm) & -0.151 & 0.370 & -0.717 & 0.399 & 0.319 & -0.254 \\
\hline Grain weight (gm) & $\mathbf{0 . 6 6 5}$ & -0.192 & -0.001 & 0.013 & -0.053 & -0.719 \\
\hline 1000 seed weight (gm) & 0.568 & 0.022 & -0.022 & 0.606 & -0.134 & $\mathbf{0 . 5 4 0}$ \\
\hline Eigen value & 2.389 & 1.2764 & 1.0261 & 0.9508 & 0.7084 & 0.6494 \\
\hline Proportion (\%) & 0.231 & 0.653 & 0.171 & 0.528 & 0.118 & 0.108 \\
\hline Cumulative (\%) & 0.531 & 0.544 & 0.615 & 0.774 & 0.892 & 0.980 \\
\hline In bold and italic fonts, the group traits with the highest positive and negative loading were displayed, respectively. \\
\hline
\end{tabular}

\section{Discussion}

Plant breeders use mutation induction, a powerful technique to establish genetic diversity in any crop with a higher frequency than random mutations (Roychowdhury and Tah, 2013). This variability can be used to pick desired characteristics. Mutagens may affect all parts of the plant, either decreasing or increasing plant traits in comparison to their parents. Their impact may either shorten or lengthen the plant's life cycle. The best concentration for high frequency mutations has been calculated to be $L_{50}$ for artificially induced mutations using physical or chemical mutagens (Mohamed et al., 2020). The $L D_{50}$ was determined in the current studies based on seed germination at various EMS concentrations and treatment times. The LD ${ }_{50}$ of two sorghum varieties, Argity and Dekeba, was determined to be $0.25 \%$ EMS in both cases. Similarly, Wanga et al. (2020) reported that the optimum EMS concentration in sorghum was $0.20-0.3 \%$ with an 8-hour treatment period. The variation in EMS $L D_{50}$ for two varieties of the same species was found to be very different, implying that it may vary from genotype to genotype (Table 1). It may be due to the fact that their genetic makeup is different. Thange et al. (2021) reported $0.2 \%$ EMS and 8 hour exposure time to be optimum $\left(\mathrm{LD}_{50}\right)$ for sorghum species, which is lower than our findings. In general, $0.25 \%$ and 8 hrs exposure time were found to be the best conditions for our bulk EMS sorghum mutagenesis. Higher mutagen concentrations, on the other hand, were associated with a higher mutation frequency. When lower concentration of EMS $(0.10 \%)$ was used, the survival rate of treated plants was higher, but the mutation rate was low as also reported by Sohail et al. (2020). The findings of this study may be used in the development of sorghum mutation breeding programs.

The lethal doses of mutagens were discarded to ensure a high prevalence of desirable mutations since the aim of this study was to grow a large mutagenized population to allow successful screening of high yielding, biotic and abiotic stress resistant mutants. The seed germination inhibition may be due to mutagen interaction with auxin synthesizing enzymes (Kamali, 2020). Pollen grain structure and physiology are genetically regulated, and any abnormal meiotic cycle can cause significant changes in pollen properties. Pollen fertility has been confirmed to be reduced after mutagen treatments in sorghum (Dhaka et al., 2020). The pollen sterility percentage was found to be significantly lower in the $M_{3}$ generation than in the $M_{2}$ generation, which explains how the recovery mechanism works between the two generations. In both sorghum types, the survival rate at maturity decreased as the mutagen dose was increased. These results back up previous sorghum research (Hao et al., 2021). Plant survival at maturity can be reduced as a result of disrupted physiological processes or cytological damage (Oliver et al.,

2020).

Increased mutation frequency is needed for crop improvement in mutation breeding. The selection of the best mutagen and concentration is crucial for obtaining desired mutations at the highest rates. Both sorghum varieties had a deferential response to EMS treatment. The different chlorophyll-deficient mutants found in $\mathrm{M}_{2}$ generation, such as albino, chlorine, xantha, tigrina, and xanthavirids, were classified (Fig. 4). Sorghum showed similar patterns of higher chlorophyll mutation frequency with increasing EMS mutagen dose (Ramkumar et al., 2019; Shi et al., 2020). The decrease in chlorophyll frequency from $\mathrm{M}_{1}$ to $M_{3}$ may be due to mutation saturation, resulting in the exclusion of mutant cells during plant growth and generation. Albino and chlorina mutants were found more frequently in both sorghum varieties in this study. The increased incidence of chlorophyll mutations demonstrates the synergistic effects of EMS (Raina, 2018).

Several morphological mutants with altered flowering date, plant height, maturity date, stem diameter, grain per head, and thousand seed weight were obtained in the $\mathrm{M}_{3}$ generation of sorghum in the current study. Despite the fact that the majority of the induced morphological mutants were uneconomical, they can be used as a source of useful genes in hybridization program. The morphological mutants are useful in gene mapping and phylogenetic studies of crops (Jiao et al., 2018). The induction of morphological mutants may be due to mutagen-induced chrsomosomal irregularity or the pleiotropic effects of 
mutated genes (Raina and Khan, 2020). The latest study of morphological mutants found a wide range of frequency and spectrum both between and within varieties. Some of the morphological mutants screened in this study (early maturity, dwarf, bold seeded, and seed color) can be used as a source of useful genes or as parents in cross breeding programs. Dwarf mutants, such as those found in this study, have previously been documented in sorghum (Sohail et al., 2020). The morphological mutants generated in this study were stable, non-segregating and true breeding. The strength of a linear relationship between two traits that is considered a function of selection, gene linkage, and pleiotropy (Sohail et al., 2020). The correlation coefficient of six quantitative traits was used to characterize the 192 mutant populations of the two sorghum cultivars. The yield was found to have a strong positive and important correlation value. Seeds per head are found to have the highest trait association with yield. The number of grains per head and the flowering date were also positively and substantially related to yield. The associated traits may have a direct effect on yield by adding to the amount of food synthesized by the plant during photosynthesis or plant physiological activities. As a result, during the mutation breeding experiment on sorghum, selection for these traits should be given equal weight to yield (Mengistu et al., 2020).

The phenotypic characterization of the mutant population in relation to the parents is a critical part of the mutation breeding program, and a thorough evaluation of the various interrelated traits, especially quantitative traits, is essential for successful selection. It was also proposed that statistical grouping methods be used to identify and classify mutants that came from the same parents (Huong et al., 2020). Multivariate analytical techniques such as cluster analysis and principal component analysis analyze several measurements on each population in order to determine genetic diversity, regardless of morphological data. Many authors have identified cluster analysis and principal component analysis as valuable statistical tools for sorting out multiple interrelated populations in plant breeding (Silva and Vermerris, 2020). Multivariate analysis was used in this study to estimate the induced diversity produced in the mutagenized population as compared to the control population. To confirm the probability of selection on the basis of yield traits, the percentage of variation explained by the yield trait is calculated. Cluster analysis and principal component analysis were used to simplify data for selection, as multivariate analysis is essentially a data reduction technique to increase breeding accuracy. To group the population based on their responsiveness to the six phenotypic markers, cluster analysis was performed on the treated and control populations. The principal component analysis was used to construct a community of phenotypic markers based on the responses of various populations to correlation.

In mutation breeding, the cluster that is the most distinct from the parental cluster can be used to select mutants in subsequent generations. The current breeding experiment used cluster analysis to split the mutant population into separate clusters that differed greatly from the respective controls. The mutagenic treatments resulted in heterogeneous populations in the two parental lines studied. In addition, members within clusters are genetically closer, while members in different clusters are separated by a greater distance. Principal component analysis of yield-related traits in $M_{3}$ populations was used in this study to categorize representative traits for phenotypic characterization of mutated sorghum populations and, as a result, to identify superior high-yielding plants for breeding in the next $\mathrm{M}_{4}$ generation. The major contributors to the genetic divergence were discovered to be yield per plant and plant height. Therefore, further selection on these traits in the following generation which lead to the isolation of more diverse yield trait mutants is important. Eniyih (2021) also indicated that the PCA could be very useful in identifying suitable lines for breeding purposes. According to the findings, quantitative phenotypic markers can be used to make a preliminary assessment of genetic diversity. The high GCV, high heritability, and genetic advance in the selected mutagenised population compared to respective parents showed the wide possibility of selection for improving yield traits in sorghum cultivars. Flowering date, grain yield per plant, and thousand seed weight (g) all have a strong and positive correlation with yield, according to character association studies. In the sorghum cultivars Argity and Dekeba, hierarchical cluster analysis divided the population of treatments and controls into four primary clusters. As a result, mutants must be selected based on a larger inter-cluster distance compared to controls and superior mean yield and yield portion efficiency. The results of the induced mutation evaluation for yield traits revealed that the various mutagenic treatments resulted in substantial inter-population divergence. The PCA showed that the yield trait contributed the most to divergence in mutant populations, indicating that the yield trait reacted well to mutagenic treatments and could be used to select high-yielding mutants. As a result, prospective breeding programs for creating elite mutant cultivars should expect high yielding mutant selection from these populations. Because of the high prevalence and wide variety of phenotypic mutations present in this population, it may be a useful source for screening desired sorghum mutants for forward and reverse genetic studies. In addition, the divergent populations could be used in a hybridization program to produce desirable segregants in future generations.

\section{Declarations}

\section{Acknowledgment}

The authors acknowledge the technical and advisory assistance provided by the National Agricultural Biotechnology Research Center and Addis Ababa University.

\section{Funding}

Addis Ababa University and the National Agricultural Biotechnology Research Center, Ethiopia thematic research sponsored the study.

\section{Author information}

Affiliation

1. Department of plant science, Salale University, Fiche, Ethiopia

Abera Takele

2. Institute of Biotechnology, Addis Ababa University, Addis Ababa, Ethiopia 
Tileye Feyisa and Abera Takele

3.Department of Microbial, Cellular and Molecular Biology, College of Natural and Computational Science, Addis Ababa University, Addis Ababa, Ethiopia

Tileye Feyisa.

4. Department of plant science, National Agricultural Biotechnology Research Center, Addis Ababa, Ethiopia

Tesfaye Disasa.

\section{Contributions}

All authors contributed to the study conception and design. Material processing and data collection

and analysis were performed by Abera Takele. He also wrote the first draft of the manuscript, and all writers provided input on the previous edition. The final manuscript was read and accepted by all contributors.

\section{Corresponding author}

Correspondence to Abera Takele.

\section{Ethics declarations}

Conflict of interest

\section{There are no conflicts of interest declared by the writers.}

\section{Ethics Approval}

Not applicable.

\section{Consent to participate}

All coauthors indicate their motivation to contribute in this research.

\section{Consent for publication}

All coauthors have read and have the same opinion to submit the manuscript.

\section{References}

Abeje, Y., T. Jemberu, and T. Jorgi. 2020. Weeding Frequency to Increase Productivity of Sorghum in Gumara-Maksegnit Watershed. ABC Journal of Advanced Research 9:31-38.

Aleme Asrate, M. 2020. Evaluation of agronomic performance, chemicl composition and invitro dry matter digestibility oflablab (lablab purpureus (I.) sweet) accessions in low land areas of sheka and bench maji zones of south west Ethiopia.

Barretto, R., R. M. Buenavista, J. L. Rivera, S. Wang, P. V. Prasad, and K. Siliveru. 2020. Teff (Eragrostis tef) processing, utilization and future opportunities: a review. International Journal of Food Science \& Technology.

Belay, B. F., and M. F. Wale. 2021. Participatory on farm evaluation of improved sorghum varieties in North Gondar areas of Ethiopia. Cogent Food \& Agriculture 7:1871809.

Belete, T. 2020. Tef (Eragrostis tef (Zucc.) Trotter) breeding, achievements, challenges and opportunities in Ethiopia; incase Southwestern Ethiopia. Journal of Genetic and Environmental Resources Conservation 8:18-31.

Biswas, S., J. Tian, R. Li, X. Chen, Z. Luo, M. Chen, X. Zhao, D. Zhang, S. Persson, and Z. Yuan. 2020. Investigation of CRISPR/Cas9-induced SD1 rice mutants highlights the importance of molecular characterization in plant molecular breeding. Journal of Genetics and Genomics 47:273-280.

Brasier, C. M., D. E. Cooke, J. M. Duncan, and E. M. Hansen. 2003. Multiple new phenotypic taxa from trees and riparian ecosystems in Phytophthora gonapodyides-P. megasperma ITS Clade 6, which tend to be high-temperature tolerant and either inbreeding or sterile. Mycological research 107:277-290.

Daigaku, Y., K. Endo, E. Watanabe, T. Ono, and K. Yamamoto. 2004. Loss of heterozygosity and DNA damage repair in Saccharomyces cerevisiae. Mutation Research/Fundamental and Molecular Mechanisms of Mutagenesis 556:183-191.

Deng, B. 2020. IMPROVING SOIL PROPERTIES WITH ACACIA SEYAL AGROFORESTRY AND BIOCHAR: IMPLICATIONS FOR SORGHUM PRODUCTION ON THE DRYLANDS OF SOUTH SUDAN. Department of Agricultural Sciences Publications 49. 
Dhaka, N., K. Krishnan, M. Kandpal, I. Vashisht, M. Pal, M. K. Sharma, and R. Sharma. 2020. Transcriptional trajectories of anther development provide candidates for engineering male fertility in sorghum. Scientific reports 10:1-16.

Eldeen, S., E. Ahmed, A. A. Jaberldar, E. Elilah, and B. M. Ahmed. 2020. Yield and Quality of Ten Forage Sorghum (Sorghum bicolor (L.) Moench) Genotypes Grown under Rain-fed in North Kordofan State. Asian Basic and Applied Research Journal:6-12.

Eniyih, Y. 2021. GENETIC VARIABILITY AND ASSOCIATION OF TRAITS IN SORGHUM [Sorghum bicolor (L.) Moench] GENOTYPES AT KOBO DISTRICT, NORTHEASTERN AMHARA, ETHIOPIA.

Gienapp, P., M. P. Calus, V. N. Laine, and M. E. Visser. 2019. Genomic selection on breeding time in a wild bird population. Evolution letters 3:142-151.

Hao, H., Z. Li, C. Leng, C. Lu, H. Luo, Y. Liu, X. Wu, Z. Liu, L. Shang, and H. C. Jing. 2021. Sorghum breeding in the genomic era: opportunities and challenges. Theoretical and applied genetics:1-26.

Hiloidhari, M., N. Bhuyan, N. Gogoi, D. Seth, A. Garg, A. Singh, S. Prasad, and R. Kataki. 2020. Agroindustry wastes: biofuels and biomaterials feedstocks for sustainable rural development. Pp. 357-388 in Refining Biomass Residues for Sustainable Energy and Bioproducts Elsevier.

Horn, L. N., and H. Shimelis. 2020. Production constraints and breeding approaches for cowpea improvement for drought prone agro-ecologies in Sub-Saharan Africa. Annals of Agricultural Sciences.

Huong, C. T., T. T. T. Anh, H. D. Tran, V. X. Duong, N. T. Trung, T. Dang Khanh, and T. Dang Xuan. 2020. Assessing Salinity Tolerance in Rice Mutants by Phenotypic Evaluation Alongside Simple Sequence Repeat Analysis. Agriculture 10:191.

Irshad, A., H. Guo, S. Zhang, and L. Liu. 2020. TILLING in cereal crops for allele expansion and mutation detection by using modern sequencing technologies. Agronomy 10:405.

Iseki, K., K. Ikazaki, and J. B. Batieno. 2021. Cowpea yield variation in three dominant soil types in the Sudan Savanna of West Africa. Field Crops Research 261:108012.

Jiao, Y., G. Burow, N. Gladman, V. Acosta-Martinez, J. Chen, J. Burke, D. Ware, and Z. Xin. 2018. Efficient identification of causal mutations thrsough sequencing of bulked F2 from two allelic bloomless mutants of Sorghum bicolor. Frontiers in plant science 8:2267.

Kamali, S. 2020. Nitroxin and arbuscular mycorrhizal fungi alleviate negative effects of drought stress on Sorghum bicolor yield thrsough improving physiological and biochemical characteristics.

Kumar, V., N. Sharma, K. K. Jaiswal, M. S. Vlaskin, M. Nanda, M. K. Tripathi, and S. Kumar. 2021. Microalgae with a truncated light-harvesting antenna to maximize photosynthetic efficiency and biomass productivity: Recent advances and current challenges. Process Biochemistry.

Mahilet, T. 2020. Evaluation of Tef [Eragrostis tef (Zucc.) Trotter] Genetic Diversity Using Morphological Characters and Microsatellite Markers.

Mahuku, G., E. Wosula, F. Kanampiu, C. Rapisarda, and G. M. Cocuzza. 2017. Integrated pest management in tropical cereal crops. Integrated pest management in tropical regions. CAB International, Wallingford, United Kingdom:47-73.

Martinez, S. A., O. Shorinola, S. Conselman, D. See, D. Z. Skinner, C. Uauy, and C. M. Steber. 2020. Exome sequencing of bulked segregants identified a novel TaMKK3-A allele linked to the wheat ERA8 ABA-hypersensitive germination phenotype. Theoretical and applied genetics 133:719-736.

Mengistu, G., H. Shimelis, M. Laing, D. Lule, and I. Mathew. 2020. Genetic variability among Ethiopian sorghum landrace accessions for major agromorphological traits and anthrsacnose resistance. Euphytica 216:1-15.

Mwadalu, R., and M. Mwangi. 2013. The potential role of sorghum in enhancing food security in semi-arid eastern Kenya: A review. Journal of Applied Biosciences 71:5786-5799.

Ndung'u, D. K. 2009. Mutagenesis and development of herbicide resistance in sorghum for protection against Striga.

Oladosu, Y., M. Y. Rafii, C. Samuel, A. Fatai, U. Magaji, I. Kareem, Z. S. Kamarudin, I. Muhammad, and K. Kolapo. 2019. Drought resistance in rice from conventional to molecular breeding: a review. International journal of molecular sciences 20:3519.

Oliver, M. J., J. M. Farrant, H. W. Hilhorst, S. Mundree, B. Williams, and J. D. Bewley. 2020. Desiccation tolerance: Avoiding cellular damage during drying and rehydration. Annual review of plant biology 71:435-460.

Parmar, A., A. Fikre, B. Sturm, and O. Hensel. 2018. Post-harvest management and associated food losses and by-products of cassava in southern Ethiopia. Food security 10:419-435.

Raina, A. 2018. Studies on the Induction and Screening of High Yielding Mutants in Cowpea [Vigna Unguiculata (L.) Walp.].

Raina, A., and S. Khan. 2020. Mutagenic effectiveness and efficiency of gamma rays and sodium azide in M2 generation of Cowpea [Vigna unguiculata (L.) Walp.]. bioRxiv. 
Ramkumar, M. K., S. Senthil Kumar, K. Gaikwad, R. Pandey, V. Chinnusamy, N. K. Singh, A. K. Singh, T. Mohapatra, and A. M. Sevanthi. 2019. A novel stay-green mutant of rice with delayed leaf senescence and better harvest index confers drought tolerance. Plants 8:375.

Richard, C., K. Munyinda, T. Kinkese, and D. S. Osiru. 2015. Genotypic variation in seedling tolerance to aluminum toxicity in historical maize inbred lines of Zambia. Agronomy 5:200-219.

Sahu, P. K., R. Sao, S. Mondal, G. Vishwakarma, S. K. Gupta, V. Kumar, S. Singh, D. Sharma, and B. K. Das. 2020. Next generation sequencing based forward genetic approaches for identification and mapping of causal mutations in crop plants: A comprehensive review. Plants 9:1355.

Sedlazeck, F. J., H. Lee, C. A. Darby, and M. C. Schatz. 2018. Piercing the dark matter: bioinformatics of long-range sequencing and mapping. Nature Reviews Genetics 19:329-346.

Shi, H., B. Geng, Y. Zhao, Y. Liu, R. Huang, P. Zhao, and Z. Guo. 2020. EMSGÇÉinduced mutations in common vetch (Vicia sativa L.) and two mutants without anthocyanin accumulation showing increased cold tolerance. Grassland Science.

Silva, T. N., and W. Vermerris. 2020. High-Biomass Sorghums as a Feedstock for Renewable Fuels and Chemicals. Sorghum in the 21st Century: FoodGÇôFodderGÇôFeedGÇôFuel for a Rapidly Changing World:723-754.

Sohail, M. N., C. K. Blomstedt, and R. M. Gleadow. 2020. Allocation of Resources to Cyanogenic Glucosides Does Not Incur a Growth Sacrifice in Sorghum bicolor (L.) Moench. Plants 9:1791.

Taheri, S., T. L. Abdullah, S. M. Jain, M. Sahebi, and P. Azizi. 2017. TILLING, high-resolution melting (HRSM), and next-generation sequencing (NGS) techniques in plant mutation breeding. Molecular breeding 37:40.

Taylor, J. R. 2019. Sorghum and Millets: Taxonomy, History, Distribution, and Production. Pp. 1-21 in Sorghum and Millets Elsevier.

Tirfessa, A., T. Tesso, A. Adugna, H. Mohammed, and D. Kiambi. 2020. Genetic diversity among Ethiopian sorghum [Sorghum bicolor (L.) Moench] gene bank accessions as revealed by SSR markers. African Journal of Biotechnology 19:84-91.

Tonapi, V. A., H. S. Talwar, A. K. Are, B. V. Bhat, C. R. Reddy, and T. J. Dalton. 2020. Sorghum in the 21st Century: Food, Fodder, Feed, Fuel for a Rapidly Changing World. Springer.

\section{Figures}

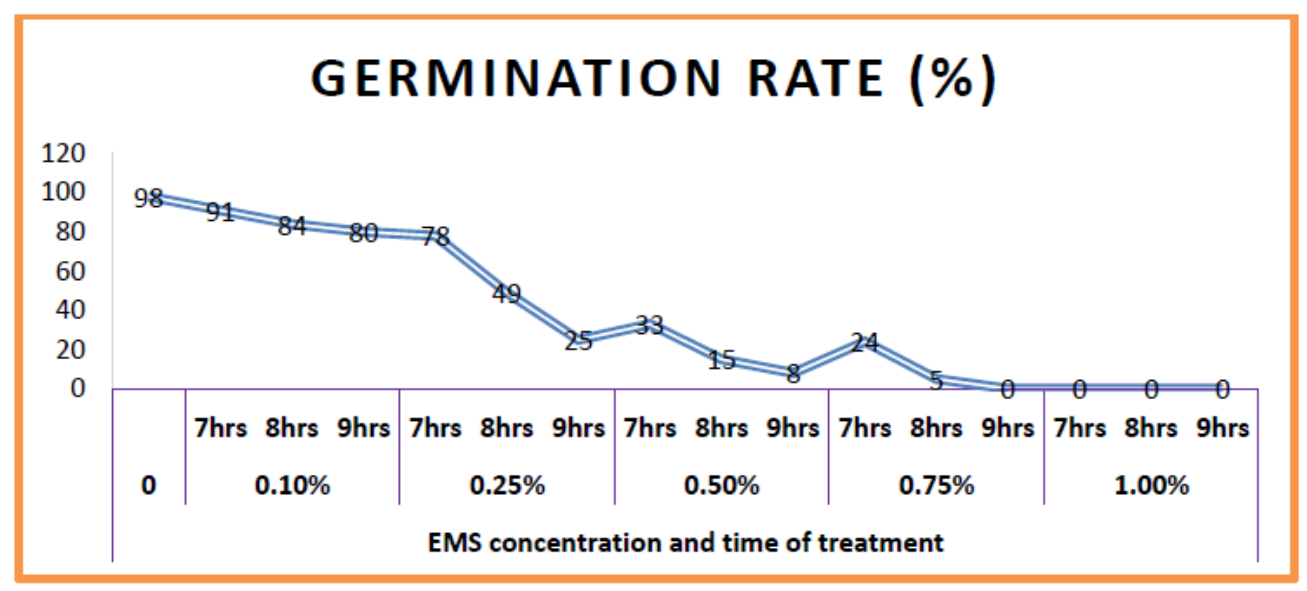

Figure 1

Germination rate plotted against EMS concentration and treatment time. 


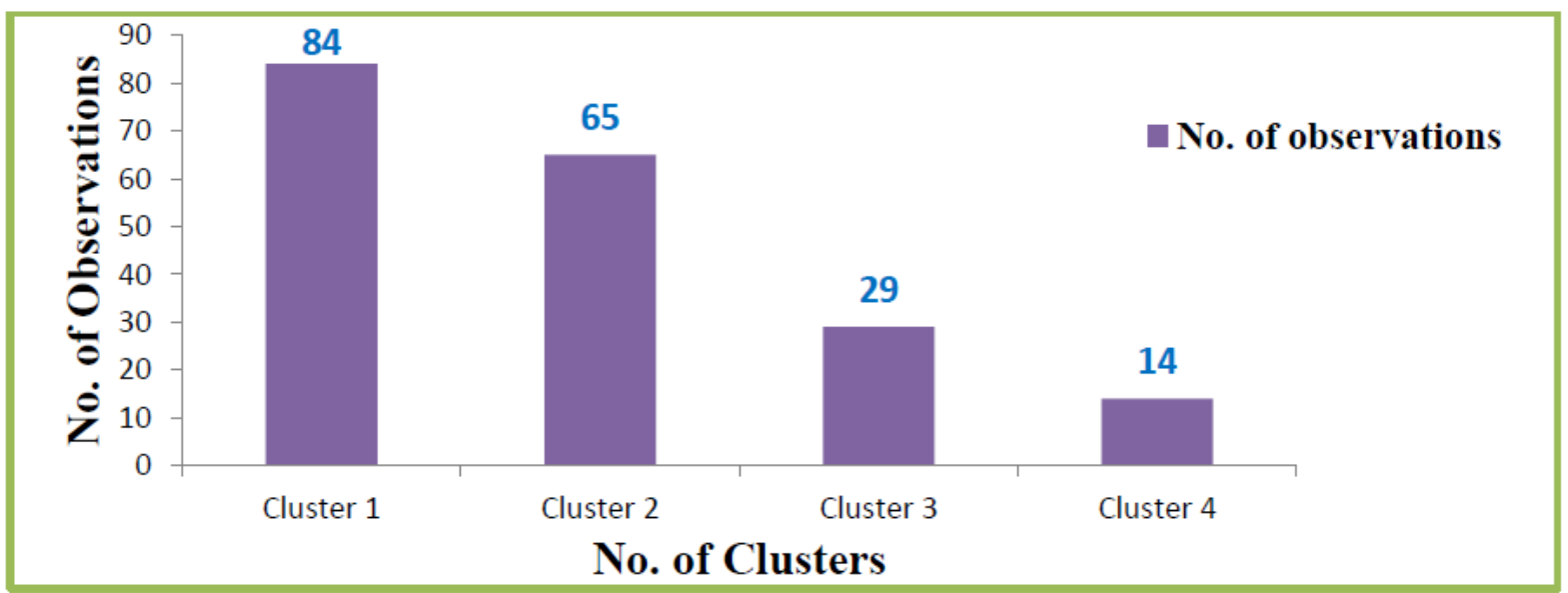

Figure 2

Clustering of mutant lines and control

\section{Dendrogram}

Complete Linkage, Euclidean Distance

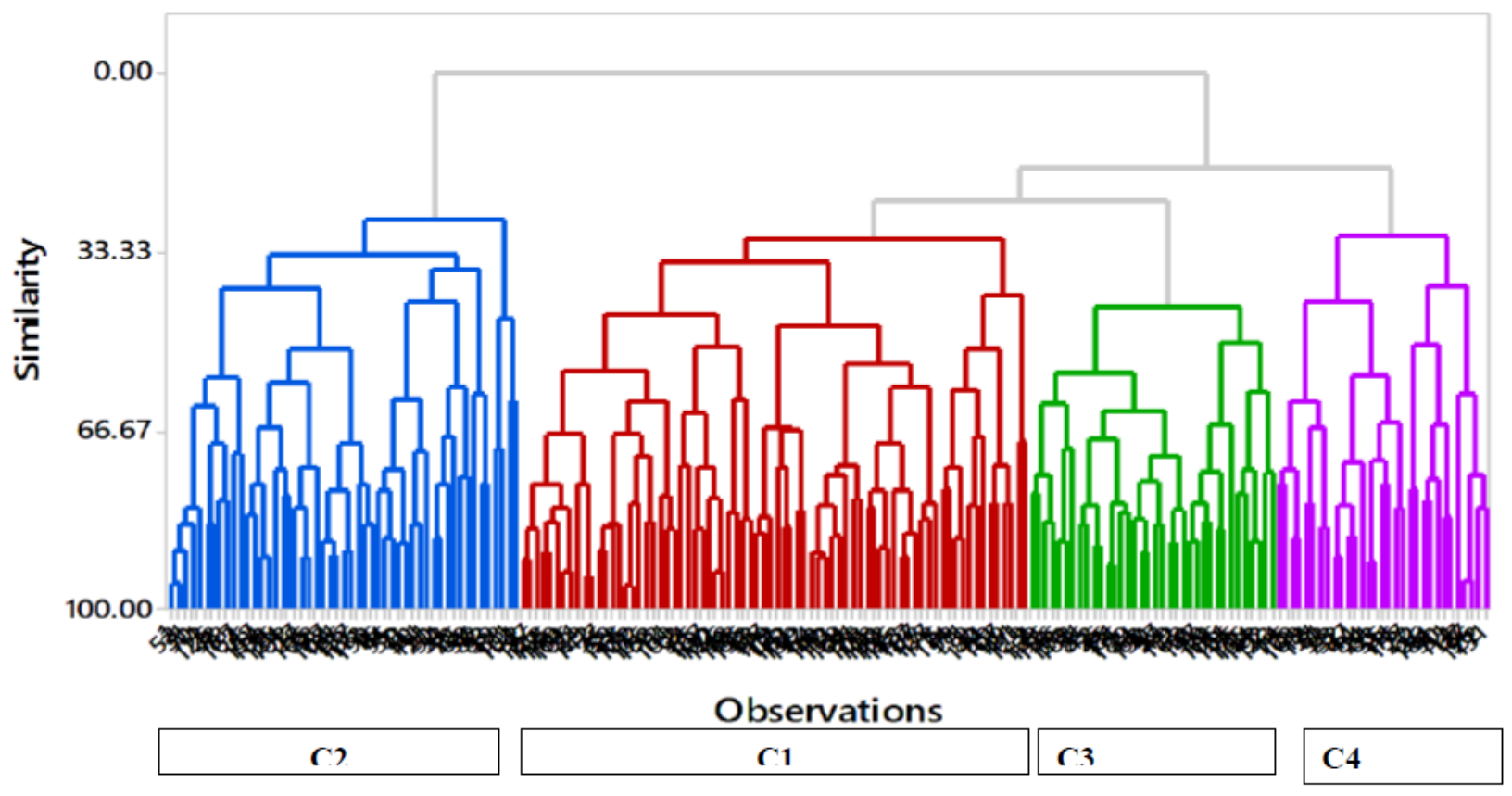

Figure 3

Dendrogram complete linkage, Euclidian distance of mutant lines 

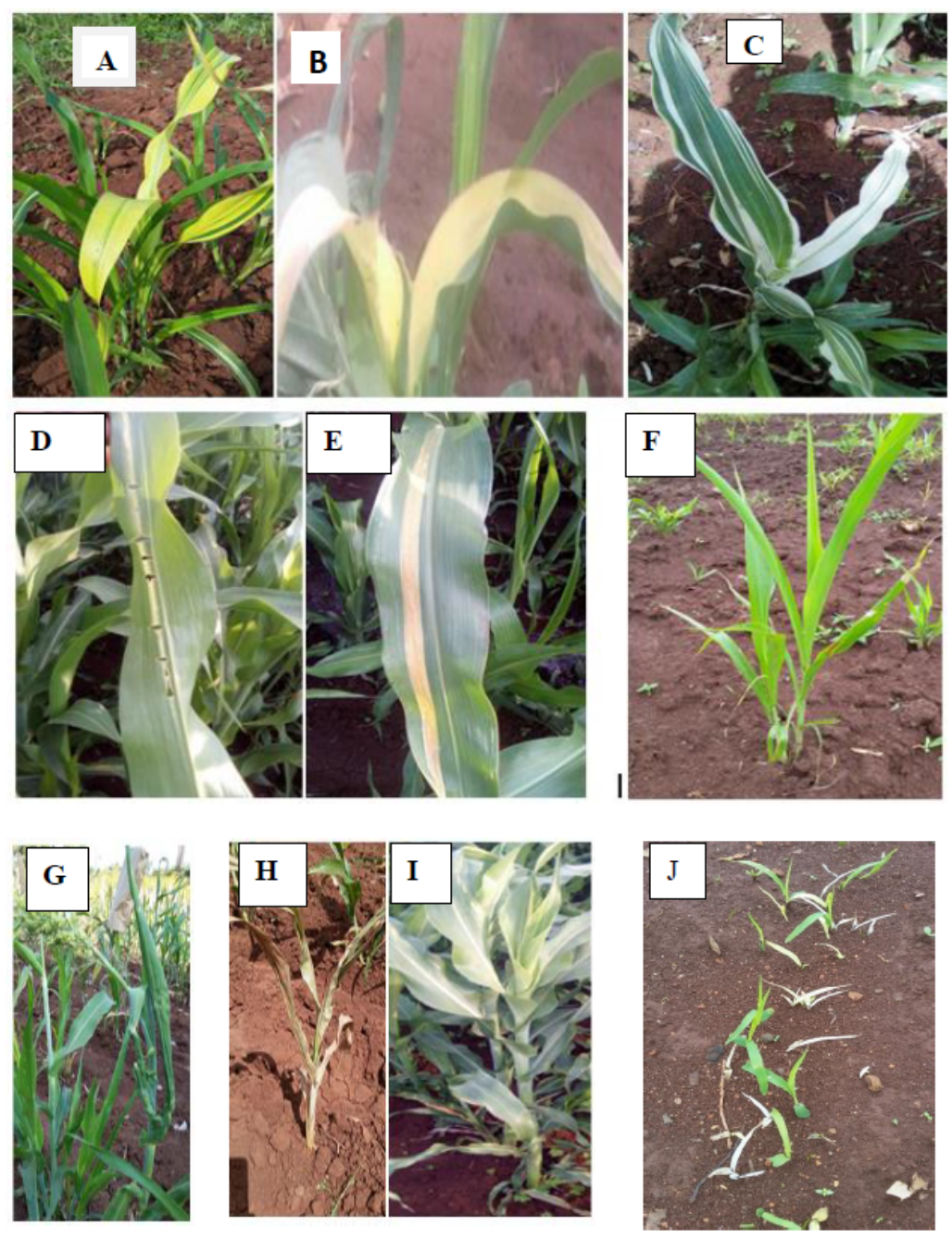

\section{Figure 4}

Phenotypic variation on plant architecture observed in M2 mutants: (A) Yelow zebra bands (B) Yellow leaf (C) White zebra cross bands (D) Spot leaf lesion (E) Yellow splotch leaf (F) Narrow leaf (G) Leaf rolling (H) Death before flowering (I) Control (J) Albino at seedling stage 